\title{
Natural remedies for diabetes mellitus
}

\author{
*Rehan Tariq ${ }^{1}$, Khalid Idrees Khan ${ }^{1}$, Rizwan Ali Masood ${ }^{1}$, Zafeer Naeem Wain ${ }^{1,2}$ \\ ${ }^{1}$ Faculty of Pharmacy, University of Central Punjab, Lahore, Pakistan \\ ${ }^{2}$ Foundation for Young Researchers, Lahore, Pakistan
}

\begin{abstract}
Diabetes is a metabolic disorder and a progressive disease that needs proper attention as uncontrolled diabetes can lead to various acute and chronic complications such as retinopathy, nephropathy, neuropathy, gastropathy etc. Pharmacological management of diabetes is costly and has certain side effects. There is a need for the usage of natural diet in the management of diabetes, as it will be cost effective, easy to use and having no side effects. Healthy individuals must also be aware of healthy eating routines. The purpose of this review article is to highlight the importance of dietary management of diabetes. More than 81 plant species have anti-diabetic activities. In this review article, some of the most commonly used natural anti-diabetic sources are mentioned, some of which have already been used for management of diabetes since ancient times.
\end{abstract}

Key Words: Hyperglycemia, Diet, Spice, Obesity, Insulin, Metabolism.

\section{INTRODUCTION}

Diabetes mellitus (DM) being a metabolic disorder is characterized by a defect in insulin secretion, its action, or both (Bastaki, 2005). Deficiency of insulin leads to chronic hyperglycemia (increased fasting and postprandial blood sugar (glucose) levels) as well as protein, fat and carbohydrate metabolism are also disturbed (Joseph and Jini, 2011).

Diabetes mellitus is classified based on its cause and clinical signs and symptoms. In general, diabetes is classified into 4 types, that are type 1 diabetes mellitus or noninsulin dependent diabetes mellitus, type 2 diabetes or insulin dependent diabetes mellitus, gestational diabetes, and other specific types. Non-insulin dependent diabetes mellitus is the major type of diabetes in younger age groups. Though the prevalence of type 1 diabetes is increasing all over the world, yet it accounts for a minority. Children of earlier age groups are more prone to type $1 \mathrm{di}$ abetes mellitus (Piero et al., 2015).

Diabetes is a complex disease that can lead to various complications; it demands a multifarious therapeutic approach. Drug therapy is provided to patients whose cells do not respond to insulin whereas insulin deficiency is managed by insulin injections in patients who show a total lack of insulin (Joseph and Jini, 2011).

*Corresponding Author:

Rehan Tariq, Research Internee

Foundation for Young Researchers

Lahore, Pakistan

E-mail: rehan.tariq79@live.com

Contact No.: +92-341-4150215

\section{TYPES OF DIABETES MELLITUS}

Diabetes mellitus has following types:

Type 1 or Insulin Dependent Diabetes Mellitus (IDDM)

Younger people (Children and adolescents) are most vulgar to Type 1 or IDDM also known as ketosis-prone or juvenile onset diabetes. IDDM is characterized by insulin deficiency and patient needs exogenous insulin for survival (Plotnick, 1994). Failure of pancreas to discharge enough insulin for the body requirements to be met is the main cause of type 1 diabetes. Glucose intolerance occurs because of progressive destruction of $\beta$-cells, as diabetes is a progressive disease. It takes months or years for enough demolishment of $\beta$-cells for the insulin dependent diabetes mellitus to appear. This destruction might be autoimmunemediated (in most cases) or it could be idiopathic destruction (Maahs et al., 2010).

\section{Risk Factors}

Only liability to Type 1 diabetes is inherited, not the disease itself. Type-1 Diabetes has a strong genetic factor. The risk of developing type 1 diabetes in children with diabetic father is $4-6 \%$, whereas those with diabetic mother it is $2-3 \%$. If one of the parents is diabetic, then the risk is $5 \%$ (Gorrell et al., 2003).

\section{Pathophysiology of IDDM}

Insulin secretion is reduced because of the damage to pancreatic $\beta$-cells, which could be in the form of autoimmune destruction. In addition, $\alpha$-cells start performing their functions abnormally as well, which cause increased discharge of glucagon in Type-1 diabetics. Blood glucose level is inversely proportional to glucagon secretion but in such patients, hyperglycemia does not suppress glucagon's secretion (Ozougwu et al., 2013). 


\section{Non-Insulin Dependent Diabetes Mellitus}

In type 2 diabetes mellitus, the first abnormality detected is abnormal sensitivity to insulin. Insulin is being produced by the pancreatic cells but their ability to produce high levels of insulin to meet the bodily demands is decreased thus causing insulinopenia, which in turn causes the development of impaired glucose tolerance and eventually the patient has to face diabetes mellitus (DeFronzo, 1992).

\section{Clinical Features}

The symptoms of Non-insulin-dependent diabetes mellitus progress slowly with the patient being asymptomatic in the beginning. Patient might face conditions like polyuria and polydipsia. Non-insulin-dependent diabetes mellitus is diagnosed during physical examination of the patient. Major symptoms include lethargy, dizziness, tiredness, leg cramps, mood swings, skin infections, itching, blurred vision and headache (Surya et al., 2014).

\section{Pathophysiology of NIDDM}

Type $2 \mathrm{DM}$ is characterized by both improperly functioning $\beta$-cells as well as $\alpha$-cells. Insulin insensitivity is the major factor in type 2 diabetes mellitus. Insulinopenia caused by destruction of $\beta$-cells result in reduced transport of glucose into the fat cells, liver and muscle cells. During fasting, breakdown of fat in increased causing hyperglycemia. The hepatic glucose and glucagon levels that increased during fasting are not suppressed with a meal. Patient faces hyperglycemia due to reduced secretion and increased resistance of insulin (Olokoba et al., 2012).

\section{Gestational diabetes}

Gestational diabetes mellitus (GDM) being firstly recognized during pregnancy is defined as glucose intolerance of variable severity (Kim et al., 2011). About $5 \%$ of pregnant females are affected by gestational diabetes mellitus and its frequency is expected to increase as the obesity increases. In the years following the pregnancy, the affected females are more vulnerable to type-2 diabetes mellitus. In addition, their children are vulnerable of getting obese as well as developing type-2 diabetes mellitus early in their life (Kampmann et al., 2015).

Majority cases of gestational diabetes mellitus can be controlled with lifestyle modifications alone. Insulin is not transferred from pregnant woman to her fetus, thus it is employed as initial line medical care. Both Metformin \& Glyburide are considered efficacious and safe, although we have no evidence of safety for their chronic use. According to ACOG, oral agents and insulin have same efficacy, so either can be employed as initial line medical care whereas NICE prefers metformin to insulin therapy (Kelley et al., 2015).

\section{Other types of Diabetes Mellitus}

Diabetes can be classified into other types based upon their etiology.

- Maturity onset diabetes in youth is characterized by abnormally functioning $\beta$-cells and this defect is genetic.

- Less than $10 \%$ are those having pancreatic disorders caused by infections, chemicals or drugs.

- Those having faulty insulin action.

- Those having cystic fibrosis or pancreatitis.

- Those having diseased endocrine gland (Baynest, 2015).

\section{COMPLICATIONS OF DIABETES}

In diabetes mellitus, either small blood vessels are damaged (micro-vascular disease) or arteries are damaged (macro-vascular disease). Micro-vascular complications include neuropathy, retinopathy and/or nephropathy. Common macro-vascular complications include cerebrovascular disease and myocardial infarction (Forbes and Cooper, 2013).

Generally, diabetic complications can be classified into 2 groups:

a) Acute metabolic complications: Short-term complications including ketoacidosis, hyperosmolar nonketonic coma and hypoglycemia.

b) Late systemic complications: Long lasting complications including retinopathy, diabetic nephropathy, atherosclerosis, diabetic neuropathy, microangiopathy and infections (Ullah et al., 2015).

\section{CURRENT MANAGEMENT OF DIABETES MELLITUS}

- $\quad$ Agents like Voglibose, acrabose and miglitol are used to manage post-prandial hyperglycemia. These agents decrease glucose absorption by the cells and thus manage diabetes at digestive level.

- Different therapies used to manage diabetes mellitus do have some limitations, as they are not cost effective and can show certain side effects like liver toxicity, weight gain, gastrointestinal disturbances as well as hypoglycemia.

- Biguanide such as metformin is used to potentiate glucose uptake by peripheral cells. Sulphonylureas like glibenclamide act as insulinotropic and work as secretagogue for pancreatic cells (Joseph and Jini, 2011). 


\section{DIETARY MANAGEMENT OF DIABETES} MELLITUS

Dietary management of diabetes pursue to attain most favorable blood lipid concentrations, suitable energy for equitable weight, normal growth and development during pregnancy and lactation, to avoid diabetic complications, and for improvement of health by consuming well balanced nutrition (Asif, 2014).

In most developed countries, $4^{\text {th }}$ or $5^{\text {th }}$ leading cause of death is diabetes mellitus which can reach to epidemic proportions in most developing and newly industrialized countries. Due to traditional lifestyle, a very few rural people are affected by type 2 diabetes mellitus (Steyn et al., 2004). To obtain good glycemic control, low intake of calories and weight loss is important. The ideal proportion of carbohydrates, fats, and proteins that should be recommended remains unclear (Ajala et al., 2016). To prevent, manage or lower the rate of development of complications of diabetes, medical nutrition therapy is important (Bantle, 2008). In case of type 1 diabetes mellitus the role of diet is doubled, it helps in maintaining the glucose level in blood almost steady as well as reduces long-term complications. When we talk about the management of diabetes with diet, the principles are same for both type 2 as well as type 1 diabetes mellitus (Bastaki, 2005).

\section{Momordica charantia}

Traditionally bitter melon is utilized in the management of diabetic complications. Resistance of insulin at cellular level is the most rudimentary defect in NIDDM patients. This resistance of insulin at cellular level causes hypertriacylglycerolaemia, increased VLDL secretion and hyperinsulinemia (Nerurkar et al., 2008). Momordica charantia exert its anti-diabetic effect by improving glucose tolerance and decreasing blood glucose levels. For diabetic patients, obesity is a major issue. Momordica charantia checks obesity as well. In addition to increasing insulin sensitivity, Momordica charantia also improves the secretion of insulin by improving the condition of damaged $\beta$-cells i-e their preservation and protection (Cummings et al., 2004).

\section{Cinnamon (Cinnamomum zeylanicum and C. verum)}

Cinnamon belongs to the Lauraceae family. Cinnamon has been used as spice in normal routine as well as medicinally since ancient times (Medagama, 2015). Cinnamon is antiinflammatory, disease lowering compound, lipid lowering, antioxidant, antimicrobial, anti-diabetic, anticancer as well as effective in neurological disorders, like Alzheimer's disease and Parkinson's disease (Rao and Gan, 2014).

\section{Cloves (Eugenia Caryophyllata or Syzygium aromaticum)} It belongs to Myrtaceae family. Clove has the potential to control blood glucose level. Clove can also be used to prevent blood clots due to the presence of eugenol in it (Milind and Deepa, 2011).
The major phenolic constituents present are caffeic acid, gallic acid, kaempferol, isoquercitrin and ellagic acid. Upon usage of powder of clove buds in rats, it is proved that this powder exhibits many useful actions like hypoglycemic activities, antioxidant activities, anti-hyperlipidemic and anti-hepatotoxic activities. It slows down digestion of carbohydrates and also checks oxidative stress (Rizvi et al., 2014).

\section{Capsicum annum}

It belongs to Solanaceae family. Serrano and Fresno are 2 different varieties of red chili powder having antihypercholesterolemic and antihyperglycemic properties. Therefore, red chili powder can be recommended for use by diabetic patients (Magied et al., 2014).

A factor that is involved in hypoglycemia might be the hindrance of reabsorption of intestinal glucose. Postprandial hyperinsulinemia could be achieved by the regular usage of chili pepper (Fathima, 2015).

\section{Coccinia indica}

Coccinia indica belongs to Cucurbitaceae family, which is abundantly grown in India and is being used traditionally for managing diabetes mellitus. In alloxan diabetic rats, Coccinia indica has proved to be hypoglycemic as well as hypolipidemic (Manjula and Ragavan, 2007). Safety and effectiveness of various parts of this plant and their derived formulations having anti-diabetic effects have also proven by various clinical trials. Coccinia indica also possess antiinflammatory, antipyretic, hepatoprotective, hypolipidemic and analgesic activities (Deokate and Khadabadi, 2011).

\section{Vaccinium myrtillus}

A natural source to maintain lower levels of blood sugar is blue berry (D Jini, 2011). Wild berries boost various health conditions, as they are anti-microbial, anti-inflammatory, anti-aging, anti-cancer, as well as anti-diabetic. High contents of phytochemicals like proanthocyanidins, flavonols, anthocyanins and phenolic acids are found in blue berries (Parmar and Rupasinghe, 2013).

\section{Trigonella foenum graecum}

It belongs to the family Fabaceae. It can prove beneficial for both type 2 as well as type 1 diabetes mellitus. Anti-diabetic and anti-hyperlipidemic effect of fenugreek is because of diosgenin and saponins. In laboratory animals and human beings, fenugreek can be used as a hypoglycemic herb (Aher et al., 2016).

Anti-diabetic activity of fenugreek seeds could be due to galactomannan-rich soluble fiber fraction. Pancreatic $\beta$ cells are directly stimulated by amino acids, thus the presence of amino acid 4-hydroxyisoleucine might be 
responsible for the anti-diabetic and insulinotropic properties. Delayed stomachic voidance and inhibition of aldohexose transport even have been postulated as potential mechanisms (Rashmi et al., 2011).

\section{Prunus dulcis}

A Seventh Day Adventists study was conducted in which it was noticed that almonds have a potential to lower postprandial blood glucose levels as well as oxidative damage in normal healthy humans. Jenkins et al. (2006) also claimed the same effect of almonds. Almond has a sweet and a bitter variety having special dietary values. They are used in cakes and biscuits as floor, as they practically contain no starch. So diabetic patients can use these cakes and biscuits (Jini, 2011).

\section{Ficus religiosa}

Common name is Peepal tree. It belongs to the Moraceae family having active constituent like $\beta$-sitosterol-D-glucoside, which has blood sugar lowering effect in rabbits that are made diabetic by Alloxan and in pituitary-diabetic rats (Chandrasekar et al., 2010). Nearly every part of this plant has various medicinal uses but we are concerned with hypoglycemic effects of the plant. Bark can be used for the management of diabetes. FRAE additionally showed vital increase in serum insulin and polyose content in skeletal muscles and liver of STZ-evoked diabetic rats whereas a vital depletion within serum triglyceride level and entire cholesterin was seen (Panchawat, 2012).

\section{Emblica officinalis}

Amla fruit has various therapeutic applications in heart diseases, hepatic disorders, cancer and diabetes as well as it is an anti-inflammatory agent. It also shows memory effects (Dasaroju and Gottumukkala., 2014). Emblica officinalis fruit has anti-diabetic effect in both healthy as well as diabetic individuals. In diabetic rats, oxidative stress was reduced, so was the neuropathic pain. It can enhance oxidative stress and glycemic status in non-insulin dependent diabetic rats. Anti-diabetic property of this fruit has also reported by many articles. The exact mechanism of its hypoglycemic activity is not yet clear (Fatima et al., 2015). Amla fruit has various health benefits. It can be used in conditions like heart diseases, ulcer prevention, cancer, and hepatotoxicity as well as in diabetes (Dasaroju and Gottumukkala, 2014).

\section{Onion (Allium cepa)}

Onion being cultivated in India, China and United States, is a part of Amaryllidaceae family. It is used as a spice in home. It contains many essential nutrients and can be used in asthma, cholera, hepatitis and stomach disease (MSH Akash et al., 2014). Its anti-diabetic properties could be due to the active constituent allyl propyl disulfide (Andallu et al., 2001). Utilization of glucose and its cellular uptake in rats, insulin release and action might be enhanced due to onion extract like glibenclamide (Ozougwu, 2011). Due to its anti-hyperglycemic and anti-hyperlipidemic effect, noninsulin dependent diabetic patients can use onions. Onions have various health benefits. It is useful in hypertension, as hypocholesterolemic, hypoglycemic, cardiovascular diseases, as well as anti-carcinogenic (Lee et al., 2013).

\section{Areca catechu}

Arecoline is the active constituent having hypoglycemic activity. Subcutaneous administration of alkaloid content of Areca catechu can have hypoglycemic activity lasting for 4/6 hours (Patel et al., 2009). It has effective glucose lowering activity in streptozotocin induced diabetic rats (Mondal et al., 2012). Areca catechu flowers caused hyperglycemic effect in fasting as well as decreased weight in controlled rats (with diabetes) compared to normal rats (Ghate et al., 2014).

\section{Camellia Sinensis}

Green tea shows various health benefits as it is antibacterial, anti-inflammatory, anti-mutagenic, anti-diabetic, antiviral as well as anti-carcinogenic. Its aqueous extract mainly contains catechins like EC, EGC, ECG, EGCG (Rani et al., 2014). By its consumption, blood glucose level was lowered in diabetic mice but it did not affect insulin level in them. If used for long time, not only it enhances insulin sensitivity but it can also prevent insulin resistance issues, anti-hypoglycemia and other metabolic defects in rats fed by fructose (Namita et al., 2012). Camellia sinensis enhanced insulin activity in STZ diabetic rats. Experiments proved that its lower doses exhibit insulinotropic effect (Patel et al., 2012).

\section{Phaseolus vulgaris}

The exact mechanism of Phaseolus vulgaris seeds is still unknown but various authors suggest that it stimulate $\beta$-cells of pancreas and hence insulin secretion is increased. Two possible mechanisms have been proposed and both of them focus on the role of $\alpha$-amylase inhibitors and phytohaemagglutinin inhibitors (Atchibri et al., 2010).

\section{Syzygium cumini}

In streptozotocin (STZ) induced diabetic rats, seed extract of Syzygium cumini has shown anti-diabetic effect. Blood glucose levels were reduced by the compounds 'Mycaminose' and methanol and ethyl acetate extract was found to reduce the blood glucose level (Kumar et al., 2014).

\section{CONCLUSION}

It was concluded that by the usage of natural diet, one could keep his blood glucose levels steady. It has been concluded that the above-mentioned natural remedies can be used for the management of diabetes. Natural plants and their extracts have effective hypoglycemic activity. Further 
research work is required on this aspect of diabetic management because natural diabetic management is convenient as well as more effective than using medicines.

\section{CORRESPONDING AUTHOR PROFILE}

Rehan Tariq is a fourth year Pharm. D student in Faculty of Pharmacy, University of Central Punjab, Lahore, Pakistan. He has keen interest in research topics related to community health issues and is actively involved in various Public Health Awareness Campaigns being conducted through platform of different NGOs.

\section{REFERENCES}

Aher, R. R., SA, B., Kadam, S. R., Kharade, S. S., Misal, A. V., \& Yeole, P. T. (2016). Therapeutic Importance of Fenugreek (Trigonella foenum-graecum L.): A Review.

Ajala, O., English, P., \& Pinkney, J. (2013). Systematic review and metaanalysis of different dietary approaches to the management of type 2 diabetes. The American journal of clinical nutrition, 97(3), 505-516. [DOI]

Akash, M. S. H., Rehman, K., \& Chen, S. (2014). Spice plant Allium cepa: Dietary supplement for treatment of type 2 diabetes mellitus. Nutrition,30(10), 1128-1137. [DOI]

Asif, M. (2014). The prevention and control the type- 2 diabetes by changing lifestyle and dietary pattern. Journal of education and health promotion, 3(1), 1. [DOI]

Atchibri, A. O. A., Brou, K. D., Kouakou, T. H., Kouadio, Y. J., \& Gnakri, D. (2010). Screening for antidiabetic activity and phytochemical constituents of common bean (Phaseolus vulgaris L.) seeds. Journal of Medicinal Plants Research, 4(17), 1757-1761.

Bantle, J. P., Wylie-Rosett, J., Albright, A. L., Apovian, C. M., Clark, N. G., Franz, M. J., ... \& Wheeler, M. L. (2008). Nutrition recommendations and interventions for diabetes: a position statement of the American Diabetes Association. Diabetes care, 31, S61-S78. [DOI]

Bastaki, A. (2005). Diabetes mellitus and its treatment. International journal of Diabetes and Metabolism, 13(3), 111

Baynest, H. W. (2015). Classification, Pathophysiology, Diagnosis and Management of Diabetes Mellitus. Journal of Diabetes \& Metabolism, 2015. [DOI]

Chandrasekar, S. B., Bhanumathy, M., Pawar, A. T., \& Somasundaram, T. (2010). Phytopharmacology of Ficus religiosa. Pharmacognosy reviews, $4(8), 195$. [DOI]

Cummings, E., Hundal, H. S., Wackerhage, H., Hope, M., Belle, M., Adeghate, E., \& Singh, J. (2004). Momordica charantia fruit juice stimulates glucose and amino acid uptakes in L6 myotubes. Molecular and cellular biochemistry, 261(1), 99-104. [DOI]

Dasaroju, S., \& Gottumukkala, K. M. (2014). Current trends in the research of Emblica officinalis (Amla): A pharmacological perspective. Inter J Pharm Sci Rev Res, 24(2), 150-159.

DeFronzo, R. A., Bonadonna, R. C., \& Ferrannini, E. (1992). Pathogenesis of NIDDM: a balanced overview. Diabetes care, 15(3), 318-368. [DOI]

Deokate, U. A., \& Khadabadi, S. S. (2011). Pharmacology and phytochemistry of Coccinia indica. Journal of Pharmacognosy and Phytotherapy, 3(11), 155-159.

Dietz, P. M., Homa, D., England, L. J., Burley, K., Tong, V. T., Dube, S. R., \& Bernert, J. T. (2011). Estimates of nondisclosure of cigarette smoking among pregnant and non-pregnant women of reproductive age in the United States. American journal of epidemiology, 173(3), 355-359. [DOI]

Fatima, N., Hafizur, R. M., Hameed, A., Ahmed, S., Nisar, M., \& Kabir, N. (2015). Ellagic acid in Emblica officinalis exerts anti-diabetic activity through the action on $\beta$-cells of pancreas. European journal of nutrition, 1-11. [DOI]

Forbes, J. M., \& Cooper, M. E. (2013). Mechanisms of diabetic complications. Physiological reviews, 93(1), 137-188. [DOI]

Ghate, R., Patil, V. P., Hugar, S., Matha, N. H., \& Kalyane, N. V. (2014). Antihyperglycemic activity of Areca catechu flowers. Asian Pacific Journal of Tropical Disease, 4, S148-S152. [DOI]

Gorrell, J. J., Williams, J. S., \& Powell, P. (2003). Review and Update of Insulin Dependent Diabetes Mellitus. The Journal of Pediatric Pharmacology and Therapeutics, 8(4), 252-265. [DOI]
Jenkins, DJA et al., (2006) Almonds Decrease Postprandial Glycemia, Insulinemia, and Oxidative Damage in Healthy Individuals. J. Nutr., 136(12): 2987-2992

Joseph, B., \& Jini, D. (2011). Insight into the hypoglycaemic effect of traditional Indian herbs used in the treatment of diabetes. Res J Med Plant, 5(4), 352-376. [DOI]

Kampmann, U., Madsen, L. R., Skajaa, G. O., Iversen, D. S., Moeller, N., \& Ovesen, P. (2015). Gestational diabetes: A clinical update. World journal of diabetes, 6(8), 1065. [DOI]

Kelley, K. W., Carroll, D. G., \& Meyer, A. (2015). A review of current treatment strategies for gestational diabetes mellitus. Drugs in context, 4. [DOI]

Kim, S. Y., England, J. L., Sharma, J. A., \& Njoroge, T. (2011). Gestational diabetes mellitus and risk of childhood overweight and obesity in offspring: a systematic review. Experimental diabetes research, 2011. [DOI]

Kumar, S., Gupta, N., Kumar, S., \& Gurjar, H. (2014). Review on some medicinal plants with antidiabetic and analgesic activity.

Lee, C. W., Lee, H. S., Cha, Y. J., Joo, W. H., Kang, D. O., \& Moon, J. Y. (2013). In vivo Investigation of anti-diabetic properties of ripe onion juice in normal and streptozotocin-induced diabetic rats. Preventive nutrition and food science, 18(3), 169-174. [DOI]

Maahs, D. M., West, N. A., Lawrence, J. M., \& Mayer-Davis, E. J. (2010) Epidemiology of type 1 diabetes. Endocrinology and metabolism clinics of North America, 39(3), 481-497. [DOI]

Magied, M. M. A., Salama, N. A. R., \& Ali, M. R. (2014). Hypoglycemic and hypocholesterolemia effects of intragastric administration of dried red chili pepper (Capsicum annum) in alloxan-induced diabetic male albino rats fed with high-fat-diet. Journal of Food and Nutrition Research, 2(11), 850-856. [DOI]

Mangalagiri Mandal, G. D. (2012). Therapeutic Applications of Almonds (Prunus amygdalus L): A Review.

Manjula, S., \& Ragavan, B. (2007). Hypoglycemic and Hypolipidemic effec of Coccinia indica Wight \& Arn in alloxan induced diabetic rats. Ancient science of life, 27(2), 34. PMCID: PMC3330846

Medagama, A. B. (2015). The glycaemic outcomes of Cinnamon, a review of the experimental evidence and clinical trials. Nutrition journal, 14(1), 1. [DOI]

Milind, P., \& Deepa, K. (2011). Clove: a champion spice. Int J Res Ayurveda Pharm, 2(1), 47-54.

Mohammed, A., Kumar, D., \& Rizvi, S. I. (2015). Antidiabetic potential of some less commonly used plants in traditional medicinal systems of India and Nigeria. Journal of Intercultural Ethnopharmacology, 4(1), 78. PMid:26401390

Mondal, S., Bhattacharya, S., \& Biswas, M. (2012). Antidiabetic activity of Areca catechu leaf extracts against streptozotocin induced diabetic rats. J Adv Pharm Educ, 2, 10-7.

Namita, P., Mukesh, R., \& Vijay, K. J. (2012). Camellia Sinensis (green tea): A review. Global Journal of Pharmacology, 6(2), 52-59.

National Diabetes Data Group. (1979). Classification and diagnosis of diabetes mellitus and other categories of glucose intolerance. Diabetes,28(12), 1039-1057. [DOI]

Nerurkar, P. V., Lee, Y. K., Motosue, M., Adeli, K., \& Nerurkar, V. R. (2008). Momordica charantia (bitter melon) reduces plasma apolipoprotein B-100 and increases hepatic insulin receptor substrate and phosphoinositide-3 kinase interactions. British journal of nutrition, 100(04), 751-759. [DOI]

Olokoba, A. B., Obateru, O. A., \& Olokoba, L. B. (2012). Type 2 diabetes mellitus: a review of current trends. Oman Med J, 27(4), 269-273. [DOI]

Ozougwu, JC (2011). Anti-diabetic effects of Allium cepa (onions) aqueous extracts on alloxan-induced diabetic Rattus novergicus. Journal of Medicinal Plants Research, 5(7), 1134-1139.

Ozougwu, J. C., Obimba, K. C., Belonwu, C. D., \& Unakalamba, C. B. (2013). The pathogenesis and pathophysiology of type 1 and type 2 diabetes mellitus. Journal of Physiology and Pathophysiology, 4(4), 46-57. [DOI]

Panchawat, S. (2012) Ficus religiosa Linn. (Peepal): A Phyto-Pharmacological Review. International Journal of Pharmaceutical and Chemical Sciences, Vol. 1 (1): 435-446.

Parmar, I., \& Rupasinghe, H. V. (2013). Antioxidant capacity and anti-diabetic activity of wild berry stem infusions.

Patel, D. K., Prasad, S. K., Kumar, R., \& Hemalatha, S. (2012). An overview on antidiabetic medicinal plants having insulin mimetic property. Asian Pacific Journal of Tropical Biomedicine, 2(4), 320-330. [DOI] 
Patil, P. R., Rakesh, S. U., Dhabale, P. N., \& Burade, K. B. (2009). Pharmacological activities of Areca catechu Linn. - A review. Journal of Pharmacy Research Vol, 2(4).

Piero, M. N., Nzaro, G. M., \& Njagi, J. M. (2015). Diabetes mellitus-a devastating metabolic disorder. Asian journal of biomedical and pharmaceutical sciences, 5(40), 1. [DOI]

Plotnick, L. (1994). Insulin-dependent diabetes mellitus. Pediatrics in review/American Academy of Pediatrics, 15(4), 137. [DOI]

Position Statement by the Canadian Diabetes Association. (1999). Guidelines for the nutritional management of diabetes mellitus in the new millennium. Can J Diabetes Care, 23(3), 56-69.

Rani, R., Nagpal, D., Gullaiya, S., \& MadanS, A. S. (2014). Phytochemical, Pharmacological and Beneficial Effects of Green Tea. International Journal of Pharmacognosy and Phytochemical Research, 6(3), 420-426.
Rao, P. V., \& Gan, S. H. (2014). Cinnamon: a multifaceted medicinal plant. Evidence-Based Complementary and Alternative Medicine, 2014. [DOI] Rashmi, Y., Rahul, K., \& Dipeeka, G. (2011). The health benefits of Trigonella foenum-graecum: A review. Int J Eng Res Appl, 1(1), 32-5.

rights are reserved by Syeda, A., \& Fathima, N. A Systemic Review on Phytochemistry and Pharmacological Activities of Capsicum annuum.

Steyn, N. P., Mann, J., Bennett, P. H., Temple, N., Zimmet, P., Tuomilehto, J., ... \& Louheranta, A. (2004). Diet, nutrition and the prevention of type 2 diabetes. Public health nutrition, 7(1a), 147-165. [DOI]

Surya, S., Salam, A. D., Tomy, D. V., Carla, B., Kumar, R. A., \& Sunil, C. (2014). Diabetes mellitus and medicinal plants-a review. Asian Pacific Journal of Tropical Disease, 4(5), 337-347. [DOI]

Ullah, A., Khan, A., \& Khan, M. I. (2015). Diabetes mellitus and oxidative stress-a concise review. Cell, 92, 321-9014220. [DOI] 